\title{
Work Schedule Irregularity and the Risk of Work-Related Injury among Korean Manual Workers
}

\author{
Won-Tae Lee ${ }^{1,2}{ }^{1}$, Sung-Shil Lim ${ }^{1,2}$, Jihyun Kim ${ }^{1}$, Sehyun Yun ${ }^{1,2}$, Jin-Ha Yoon ${ }^{2,3}$ and \\ Jong-Uk Won $1,2, * \mathbb{D}$ \\ 1 Department of Occupational and Environmental Medicine, Severance Hospital, Yonsei University College of \\ Medicine, Seoul 03722, Korea; lewot20@yuhs.ac (W.-T.L.); lssmail@yuhs.ac (S.-S.L.); \\ jihyun0924@yuhs.ac (J.K.); yunsehyun@yuhs.ac (S.Y.) \\ 2 The Institute for Occupational Health, Yonsei University College of Medicine, Seoul 03722, Korea; \\ flyinyou@yuhs.ac \\ 3 Department of Preventive Medicine, Yonsei University College of Medicine, Seoul 03722, Korea \\ * Correspondence: juwon@yuhs.ac; Tel.: +82-2-2228-1579
}

Received: 11 September 2020; Accepted: 16 October 2020; Published: 19 October 2020

\begin{abstract}
Work schedules comprise various variables and generate health and safety outcomes, including work-related injury, which causes socioeconomic problems, such as productivity loss and damage to worker health. We investigated the association between work schedule irregularity and the incidence of work-related injury among South Korean manual workers using data from the 5th Korean Working Conditions Survey. In total, 18,330 manual workers were included. A multivariate logistic regression analysis was performed to understand the association between work schedule and work-related injury and the influence of sufficient safety information and work schedule on work-related injury. We calculated the influence of an irregular work schedule on occupational injury after controlling for personal and work environment-related factors. The adjusted odds ratio (OR) for work-related injury was 1.66 (95\% confidence interval (CI) 1.32-2.09) for an irregular work schedule. The interaction had an additive effect when the work schedule was irregular, even when sufficient safety information was provided. Manual workers had a higher incidence of injury (2.1\%). Even in adjusted analyses, work schedule irregularity conferred greater risks of work injury, particularly when not working the same number of days weekly (OR 1.52, 95\% CI 1.21-1.90). Policymakers and health professionals need to consider the impact of work schedule irregularity on worker safety and health.
\end{abstract}

Keywords: work schedule; shift work; schedule irregularity; work-related injury

\section{Introduction}

A work schedule comprises various variables—such as work hours, shift work, and break times between work - that are related to different health conditions, including fatigue and chronic disease. To date, numerous studies have reported the effects of shift work and working hours on workers' health [1-7]. Kecklund and Axelsson reviewed the side effects of shift work with regard to hypertension, type 2 diabetes, stroke, cardiovascular disease, and breast cancer [8]. Studies have investigated the effects of work schedules on other health and safety outcomes, such as lack of sufficient sleep and stress $[9,10]$.

Work-related injury is a global problem that affects communities and families. To prevent injuries, efforts are needed not only at the individual level but also at the organizational and governmental levels that can effect changes in policies [11]. Furthermore, injury is extremely important in occupational health; it results in an increased number of workdays lost due to injury, leading to the loss of 
productivity, an increase in compensation costs and medical costs, and ultimately damaging the health of workers [12].

Various factors influence work-related injuries, including age, education, gender, occupational factors, and work environments $[7,13,14]$. Occupational factors are estimated to cause 8.8 percent of deaths globally [15]. Manual workers are more frequently exposed to injury than other occupational groups due to ergonomic risk factors and factors associated with poor work environments [16-19]. Mining, construction, and manufacturing were the top three industries for industrial accidents [20]. According to the industrial disaster statistics of the Korea Safety and Health Agency, 94,000 cases of work-related injuries occurred in 2019, with 850 people succumbing to the injuries. As injuries are preventable, it is important to identify vulnerable groups, adopt preventive measures, and appropriately manage risks.

In this study, we aimed to analyze the association between the irregularity of work schedules and work-related injuries in Korean manual workers. Our study provides insight into these factors, which could form the foundation for the management of workplace environments and policy improvement.

\section{Materials and Methods}

\subsection{Study Design}

This study performed a secondary analysis of data from the 5th Korean Working Conditions Survey (KWCS) conducted in 2017. The survey questionnaire was developed on the basis of the European Working Conditions Survey (EWCS), conducted in Europe, and the UK Labour Force Survey [21]. The KWCS was aimed at improving worker safety and health through understanding the overall work environment of Korean workers and ascertaining their exposure to risk factors. To identify a representative sample of the economically active population, only workers aged $\geq 15$ years at the time of the interview, working for wages or profits for an hour or more per week, were targeted. All the KWCS participants provided informed consent for voluntary participation; the KWCS is a nationwide open-source database that protects the anonymity and privacy of the participants. The raw data can be downloaded from the Korea Occupational Safety and Health Agency website. A previous study investigated the validity and reliability of this data [22]. In this study, we analyzed the data of only the manual worker group among the following occupational classifications: skilled workers in agriculture, forestry, and fisheries; skilled workers and related workers; equipment and machine operators; and assembly workers, simple laborers, and soldiers.

\subsection{Outcomes and Variables}

The respondents were asked if they had any health problems related to injuries sustained in the last 12 months and whether the injury was related to their work. We included only work-related injuries and excluded other injuries. During the survey, the respondents were asked about their work schedule. We evaluated whether the length of work hours was the same every week, whether the number of work days was the same every week, whether the weekly work shift was fixed, and whether the start and end time of each shift was fixed. From this information, we defined the "work schedule regularity" as a variable when all four variables were satisfied. The individual participant characteristics included gender, age, and education level, and the occupational factors included work hours, the sufficient provision of safety information, night work, and the size of the workplace. Age was classified as $<39$, $40-49,50-59$, or $\geq 60$ years. The level of education was classified as elementary school or below, middle and high school, or university or higher. Work hours were divided, in accordance with the Korean Labor Standards Act, into $<40,41-52$, or $>53 \mathrm{~h}$; the legal limit of work hours is $52 \mathrm{~h}$. The size of the workplace was categorized as small (1-49 employees), medium (50-249 employees), or large (>250 employees). Out of 50,205 respondents to the KWCS, we selected 19,080 manual worker subjects. We excluded 17 individuals whose personal data were not complete. Additionally, 733 individuals who did not have work environment data related to their working hours, work regularity, and the provision 
of safety information were excluded. Thus, we included a study population of 18,330 manual workers with $11,266(61.5 \%)$ men and $7064(38.5 \%)$ women and a total of 377 work-related injuries.

\subsection{Statistical Analysis}

A frequency analysis of gender, age, final educational level, and workplace scale was conducted to show the demographic and occupational characteristics of manual workers. The differences in work-related injuries according to these characteristics were verified using the chi-square test. To understand the correlation between irregular work schedule and the dependent variable, work-related injuries, a multivariate logistic regression analysis was performed after controlling for the personal characteristics of workers and work environment-related factors. Model A involved crude analysis, Model B controlled for individual characteristics, and Model $C$ showed the odds ratio (OR) by controlling the factors in Model B along with the workplace environment factors, such as work hours, night work, the provision of safety information, and the size of the workplace. The stratification by working hours was analyzed to determine whether working hours had an impact on the effects caused by irregular work schedules. Moreover, we analyzed the interaction between the provision of safety information and the work schedule on work-related injury. All the $p$-values are two-tailed, and $p$-values $<0.05$ were considered statistically significant. We analyzed all the data using SAS version 9.4 (SAS Institute, Cary, NC, USA).

\section{Results}

Table 1 displays the relationship between the personal factors, work environment-related factors, and work-related injuries. The results revealed a statistically significant correlation between demographic characteristics, such as gender and educational level, and work-related injuries. The male manual workers experienced more injuries than their female counterparts ( $2.3 \%$ males vs. $1.7 \%$ female with $p=0.011$ ). The prevalence of injury was $1.7 \%, 2.1 \%$, and $2.8 \%$ in workers with an elementary school, middle and high school, and college or higher level of education, respectively, with $p=0.046$. Among the work environment-related factors, work hours, the size of the workplace, the sufficient provision of safety information, night work, and regular work schedules correlated with work-related injuries. The proportion of injuries was higher among those who worked more than the legally permissible $52 \mathrm{~h}(2.8 \%)$ than among those who worked for less than $40 \mathrm{~h}(1.7 \%)$; similarly, it was higher among those who did not receive sufficient safety information (2.5\%) than among those who were well informed $(1.8 \%)$. The chance of injury was higher when the work schedule was irregular $(2.6 \%)$ than when it was regular $(1.5 \%)$, with $p<0.001$. 
Table 1. General characteristics of the study population and the status of work-related injury according to individual and occupational characteristics.

\begin{tabular}{|c|c|c|c|c|c|c|c|}
\hline \multirow{3}{*}{ Characteristics } & \multirow{2}{*}{\multicolumn{2}{|c|}{ Total }} & \multicolumn{4}{|c|}{ Work-Related Injury } & \multirow{3}{*}{$p$-Value } \\
\hline & & & \multicolumn{2}{|c|}{ Yes } & \multicolumn{2}{|c|}{ No } & \\
\hline & $n$ & $\%$ & $n$ & $\%$ & $n$ & $\%$ & \\
\hline Gender & & & & & & & 0.011 \\
\hline Male & 11,266 & $(61.5)$ & 256 & $(2.3)$ & 11,010 & $(97.7)$ & \\
\hline Female & 7064 & $(38.5)$ & 121 & (1.7) & 6943 & $(98.3)$ & \\
\hline Age (years) & & & & & & & 0.369 \\
\hline$\leq 39$ & 2349 & $(12.8)$ & 40 & (1.7) & 2309 & $(98.3)$ & \\
\hline $40-49$ & 2887 & $(15.8)$ & 66 & (2.3) & 2821 & $(97.7)$ & \\
\hline $50-59$ & 4901 & $(26.7)$ & 109 & $(2.2)$ & 4792 & $(97.8)$ & \\
\hline$\geq 60$ & 8193 & $(44.7)$ & 162 & $(2.0)$ & 8031 & $(98.0)$ & \\
\hline Educational level & & & & & & & 0.046 \\
\hline Elementary school & 4176 & $(22.8)$ & 104 & $(2.5)$ & 4072 & $(97.5)$ & \\
\hline $\begin{array}{l}\text { Middle and high } \\
\text { school }\end{array}$ & 11,027 & $(60.2)$ & 220 & $(2.0)$ & 10,807 & $(98.0)$ & \\
\hline College & 3127 & $(17.1)$ & 53 & (1.7) & 3074 & $(98.3)$ & \\
\hline Work hours (h) & & & & & & & $<0.001$ \\
\hline$\leq 40$ & 9166 & $(50.0)$ & 157 & (1.7) & 9009 & $(98.3)$ & \\
\hline $41-52$ & 4902 & $(26.7)$ & 102 & $(2.1)$ & 4800 & (97.9) & \\
\hline$\geq 53$ & 4262 & $(23.3)$ & 118 & $(2.8)$ & 4144 & $(97.2)$ & \\
\hline $\begin{array}{l}\text { Size of the } \\
\text { workplace }\end{array}$ & & & & & & & 0.006 \\
\hline Small & 15,648 & $(85.4)$ & 343 & $(2.2)$ & 15,305 & $(97.8)$ & \\
\hline Middle & 1484 & $(8.1)$ & 16 & (1.1) & 1468 & $(98.9)$ & \\
\hline Large & 1198 & (6.5) & 18 & (1.5) & 1180 & (98.5) & \\
\hline $\begin{array}{l}\text { Provision of safety } \\
\text { information }\end{array}$ & & & & & & & 0.003 \\
\hline Sufficient & 10,588 & $(57.8)$ & 189 & (1.8) & 10,399 & $(98.2)$ & \\
\hline Insufficient & 7742 & $(42.2)$ & 188 & $(2.4)$ & 7554 & $(97.6)$ & \\
\hline Night work & & & & & & & 0.436 \\
\hline Day work & 16,482 & $(89.9)$ & 344 & $(2.1)$ & 16,138 & $(97.9)$ & \\
\hline Night work & 1848 & $(10.1)$ & 33 & (1.8) & 1815 & (98.2) & \\
\hline $\begin{array}{l}\text { Work schedule } \\
\text { regularity * }\end{array}$ & & & & & & & $<0.001$ \\
\hline Regular & 8667 & $(47.3)$ & 128 & (1.5) & 8539 & $(98.5)$ & \\
\hline Irregular & 9663 & $(52.7)$ & 249 & (2.6) & 9414 & $(97.4)$ & \\
\hline $\begin{array}{c}\text { Daily working } \\
\text { hours }\end{array}$ & & & & & & & $<0.001$ \\
\hline Fixed & 10,927 & $(59.6)$ & 186 & (1.7) & 10,741 & $(98.3)$ & \\
\hline Not fixed & 7403 & $(40.4)$ & 191 & $(2.6)$ & 7212 & $(97.4)$ & \\
\hline $\begin{array}{c}\text { Weekly working } \\
\text { days }\end{array}$ & & & & & & & $<0.001$ \\
\hline Fixed & 12,093 & $(66.0)$ & 210 & (1.7) & 11,883 & $(98.3)$ & \\
\hline Not fixed & 6237 & $(34.0)$ & 167 & (2.7) & 6070 & $(97.3)$ & \\
\hline Weekly work shift & & & & & & & 0.518 \\
\hline Fixed & 11,451 & $(62.5)$ & 229 & $(2.0)$ & 11,222 & $(98.0)$ & \\
\hline Not fixed & 6879 & (37.5) & 148 & $(2.2)$ & 6731 & $(97.8)$ & \\
\hline $\begin{array}{l}\text { Start and end time } \\
\text { of each shift }\end{array}$ & & & & & & & $<0.001$ \\
\hline Fixed & 11,417 & $(62.3)$ & 198 & (1.7) & 11,219 & $(98.3)$ & \\
\hline Not fixed & 6913 & $(37.7)$ & 179 & (2.6) & 6734 & $(97.4)$ & \\
\hline Total & 18,330 & $(100.0)$ & 377 & $(2.1)$ & 17,953 & $(97.9)$ & \\
\hline
\end{tabular}

Work schedule regularity * is "regular" when the daily working hours, weekly working days, weekly work shift, and start and end time of each shift are all "fixed". 
Table 2 displays the influence of irregular work schedules on occupational injury after controlling for personal characteristics and work environment-related factors. In Model A, the crude ORs of work-related injury were significant, except for that in the fixed weekly work shift; we observed a similar tendency in Model B, which was controlled only for personal characteristics. Model C was controlled for personal characteristics and work environment-related factors. It revealed an adjusted OR of 1.44 (95\% CI 1.16-1.80) when the daily working hours were not fixed, 1.52 (95\% CI 1.21-1.90) when the weekly work shift was not fixed, and 1.37 (95\% CI 1.09-1.73) when the start and end time of each shift was not fixed. The overall work schedule regularity showed an OR of 1.66 (95\% CI 1.32-2.09). Thus, in the case of manual labor, the risk of work-related injuries was higher in those with irregular work schedules.

Table 2. Odds ratio and 95\% confidence intervals for work-related injury in models A, B, and C.

\begin{tabular}{|c|c|c|c|c|c|c|}
\hline \multirow{2}{*}{ Variables } & \multicolumn{2}{|c|}{ Model A } & \multicolumn{2}{|c|}{ Model B } & \multicolumn{2}{|c|}{ Model C } \\
\hline & ORs & $95 \%$ CIs & ORs & $95 \%$ CIs & ORs & $95 \%$ CIs \\
\hline \multicolumn{7}{|c|}{ Work schedule regularity * } \\
\hline Regular & 1.00 & & 1.00 & & 1.00 & \\
\hline Irregular & 1.77 & $1.42-2.19$ & 1.73 & $1.39-2.17$ & 1.66 & $1.32-2.09$ \\
\hline \multicolumn{7}{|c|}{ Daily working hours } \\
\hline Fixed & 1.00 & & 1.00 & & 1.00 & \\
\hline Not fixed & 1.53 & $1.25-1.88$ & 1.52 & $1.22-1.88$ & 1.44 & $1.16-1.80$ \\
\hline \multicolumn{7}{|c|}{ Weekly working days } \\
\hline Fixed & 1.00 & & 1.00 & & 1.00 & \\
\hline Not fixed & 1.56 & $1.27-1.91$ & 1.53 & $1.23-1.91$ & 1.52 & $1.21-1.90$ \\
\hline \multicolumn{7}{|c|}{ Weekly work shift } \\
\hline Fixed & 1.00 & & 1.00 & & 1.00 & \\
\hline Not fixed & 1.08 & $0.87-1.33$ & 1.02 & $0.82-1.27$ & 0.99 & $0.79-1.24$ \\
\hline \multicolumn{7}{|c|}{$\begin{array}{l}\text { Start and end time of each } \\
\text { shift }\end{array}$} \\
\hline Fixed & 1.00 & & 1.00 & & 1.00 & \\
\hline Not fixed & 1.51 & $1.23-1.85$ & 1.53 & $1.22-1.91$ & 1.37 & $1.09-1.73$ \\
\hline
\end{tabular}

Work schedule regularity ${ }^{*}$ is regular when the daily working hours, weekly working days, weekly work shift, and start and end time of each shift are all "fixed". Model A: unadjusted; Model B: adjusted for age, gender, and education; and Model C: adjusted for age, gender, education, work hours, night work, the provision of safety information, and the size of the workplace. OR, odds ratio; CI, confidence interval.

Table 3 displays the results of the stratification analysis for working hours. All the analyses were adjusted for all personal characteristics and work environment-related factors, except working hours. The risk of irregularity was higher in subgroups working for more than $52 \mathrm{~h}$ (OR 2.61, 95\% CI 1.33-2.38) than in those working for less than $52 \mathrm{~h}$ (OR 2.05, 95\% CI 1.52-2.76). The results for the remaining factors were similar to those in the non-stratification analysis.

We analyzed the interaction to see how it affected work-related injury depending on the provision of safety information and the regularity of work schedules (Figure 1). Compared with a reference group with a regular schedule and sufficient safety information provided, the risk was statistically significant when the work schedule regularity was irregular and sufficient safety information was present, and it was higher when safety information was not provided. Fixed daily working hours (OR $1.78,95 \%$ CI 1.33-2.38), fixed weekly working days (OR 1.85, 95\% CI 1.37-2.51), and having a fixed start and end time for each shift (OR 1.69, 95\% CI 1.27-2.24) showed a similar tendency for work-related injuries as that of work schedule regularity (OR 2.02, 95\% CI 1.50-2.72); however, in the case of the fixity of the weekly work shift, the OR was not significant for differences between the provision and non-provision of sufficient safety information. 
Table 3. Odds ratio and 95\% confidence intervals for work-related injury in stratification analysis for working hours.

\begin{tabular}{|c|c|c|c|c|}
\hline \multirow{2}{*}{ Variables } & \multicolumn{2}{|c|}{ Working Hours ( $\leq 52 \mathrm{~h}$ ) } & \multicolumn{2}{|c|}{ Working Hours ( $>52 \mathrm{~h}$ ) } \\
\hline & ORs & $95 \%$ CIs & ORs & $95 \%$ CIs \\
\hline \multicolumn{5}{|c|}{ Work schedule regularity * } \\
\hline Regular & 1.00 & & 1.00 & \\
\hline Irregular & 2.05 & $1.52-2.76$ & 2.61 & $1.64-4.16$ \\
\hline \multicolumn{5}{|c|}{ Daily working hours } \\
\hline Fixed & 1.00 & & 1.00 & \\
\hline Not fixed & 1.62 & $1.23-2.12$ & 1.59 & $1.05-2.42$ \\
\hline \multicolumn{5}{|c|}{ Weekly working days } \\
\hline Fixed & 1.00 & & 1.00 & \\
\hline Not fixed & 1.81 & $1.38-2.38$ & 2.06 & $1.34-3.15$ \\
\hline \multicolumn{5}{|c|}{ Weekly work shift } \\
\hline Fixed & 1.00 & & 1.00 & \\
\hline Not fixed & 1.06 & $0.81-1.39$ & 0.99 & $0.79-1.24$ \\
\hline \multicolumn{5}{|c|}{ Start and end time of each shift } \\
\hline Fixed & 1.00 & & 1.00 & \\
\hline Not fixed & 1.47 & $1.01-1.96$ & 1.54 & $0.97-2.44$ \\
\hline
\end{tabular}

Work schedule regularity * is regular when the daily working hours, weekly working days, weekly work shift, and start and end time of each shift are all "fixed". Adjusted for age, gender, education, night work, the provision of safety information, and the size of the workplace. OR, odds ratio; CI, confidence interval.

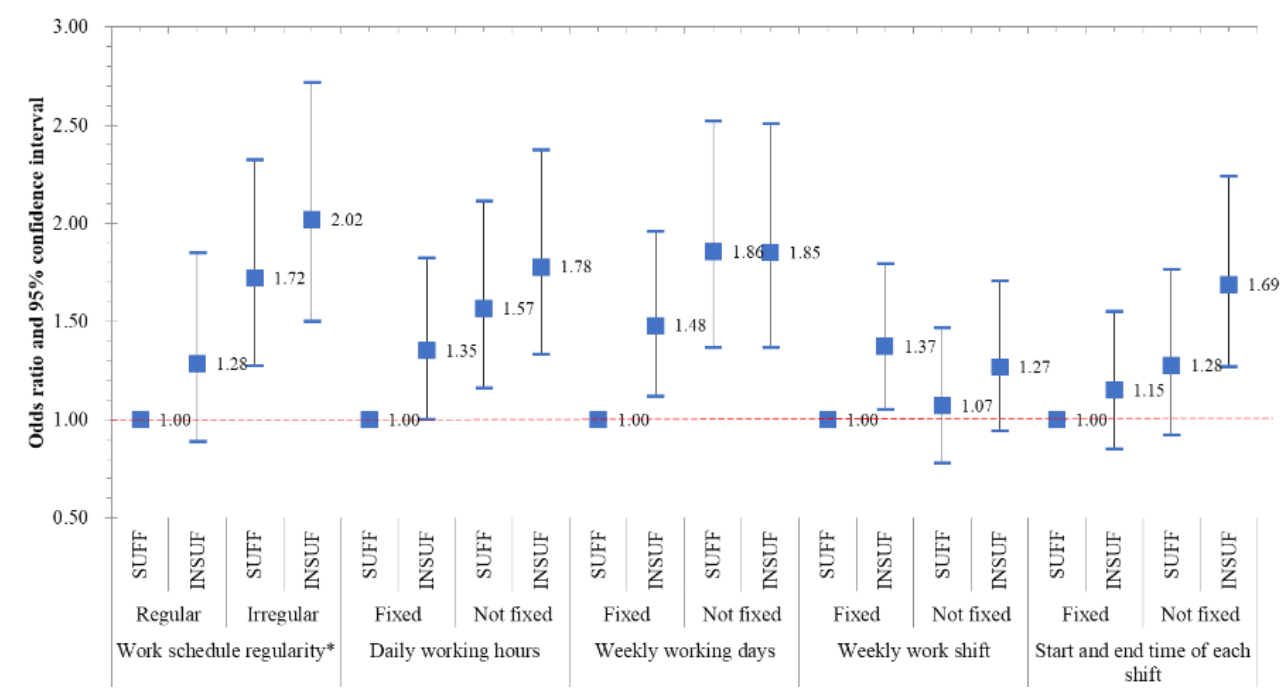

Figure 1. Odds ratio of work-related injuries according to work schedule regularity with sufficiently and insufficiently provided safety information. Work schedule regularity * is regular when the daily working hours, weekly working days, weekly work shift, and start and end time of each shift are all "fixed". "SUFF" means that sufficient safety information was provided. All the models were controlled for age, gender, education level, the size of the workplace, and work hours.

\section{Discussion}

In this study, we investigated the effects of the irregularity of work schedules on the risk of work-related injuries among manual workers. In 2018, 0.48\% of all Korean workers suffered occupational injuries. Manual workers, such as those in construction and manufacturing, are more likely to be injured than other workers [23-25]. In our study, the incidence of work-related injuries was $2.1 \%$ over 12 months in the manual workers group, indicating that they have a higher likelihood of sustaining injuries. With regard to personal characteristics, occupational injuries were common in men and less educated groups (Table 1), as reported previously [23,25]. In Australia, most of the injuries in blue-collar workers and those in small workplaces were visible and unmanaged [18]. In the 
case of work environment-related factors, injuries were higher when the work hours exceeded $52 \mathrm{~h}$ (Table 3) [26]. This is consistent with the results of a study that found that longer work hours increased the rate of industrial accidents $[27,28]$. A prospective study on construction workers in the USA determined that the risk of severe work-related injury increased (OR 1.98) when work hours exceeded $50 \mathrm{~h}$ per week [29]. Many studies have shown that work-related injuries occur more frequently in shift work than in non-shift work. When a worker changed from day work to non-standard shift work, the OR for occupational injuries increased to 2.6 (95\% CI 1.79-3.77) [2,27]. The results of the logistic regression analysis (Table 2) suggested that irregular work schedules induce a greater risk of work injuries, even when personal and other occupational factors, such as work hours, are controlled. In particular, the number of workdays in a week correlated with the highest risk of occupational injuries (OR 1.52, 95\% CI 1.21-1.90). We conducted the stratification analysis assuming working hours as a confounder, but there was no change in the results (Table 3). Thus, the weekly working hours did not influence the association between the irregularity of the work schedule and the incidence of injury. According to Kang et al., working hours can modify the risk of workplace injury [28], but the cross-sectional nature of our research design could not measure these socio-biological selection biases, so-called health worker effects [30].

Moreover, the irregularity of work schedules and the provision of safety information had an additive effect on occupational injury. Our findings indicate that the risk of injury was greater when sufficient safety information was not provided (Figure 1) [31-33]. Furthermore, among the variables, the highest risk was noted for the same number of workdays per week with the variation in total schedule regularity. This suggests that if the number of workdays per week varies, the probability of working on a weekend increases, and, consequently, time lost from work due to occupational injury increases [34,35]. In particular, in women the percentage of lost time due to injury on Sundays or Saturdays increased by approximately $122 \%$ and $60 \%$, respectively [34]. This may be caused by differences in the level of supervision on the weekends as several other events occur, such as social activities and late dining; additionally, alcohol consumption may increase on the weekends [36]. Moreover, working different hours each week indicate a fluctuation in job demand, which can directly cause work-related injury; as the job demand increases, injuries can occur through mechanisms that affect job-related stress and musculoskeletal disorders [17,37].

The strength of our research is that it analyzes, for the first time, the relationship between work injuries on a large scale and irregularities in work schedules in manual workers. The study utilized well-established surveys for the entire population and analyzed the occupational factors for health after controlling for individual characteristics. In addition, our study has the advantage that the risk factors were analyzed using the regularity of the work schedule, which is applicable to workers who were not performing shift work.

This study has its limitations. The data used in this study are from a cross-sectional survey, and therefore the prognostic relationship cannot be identified in the relationship between the irregularity of the work schedule and work-related injury. Therefore, further prospective research is needed to clarify causality in this context. However, the data are relatively robust, as they were sampled from all categories of workers, including manual laborers, throughout the country. Several human and environmental factors influence the risk of injury: unsafe acts, health conditions, physical (ergonomic) and chemical hazards of the workplace, and job-related stress [38,39]. We adjusted other confounders available in this dataset, but because of the data limitations, various other factors could not be analyzed. Nonetheless, in this study we confirmed that an irregular work schedule influences work-related injuries even after adjusting for working hours and shift work, which are important factors that cause injury. In addition, when measuring injury, the data were inadequate to ascertain the exact mechanism of injury because the data were based on self-reports, which are not objective. Despite that, the severe occupational injuries that we wanted to investigate would not be overestimated without bias. Notwithstanding these limitations, our results directly address the suspected risk factors that may be related to workplace injuries. 


\section{Conclusions}

We analyzed the influence of the regularity of work schedules on work-related injuries after controlling for personal and work environment-related factors among manual workers. Even when the work hours and work environments, which have recently been a topic of discussion, were consistent, our results confirmed that an irregular work schedule is the main factor that affects worker safety and health. Thus, these analyses provide useful insight for improving the work environment for the health promotion of workers. Policymakers need to consider how irregular work schedules affect worker safety and health.

Author Contributions: Conceptualization, W.-T.L. and J.-U.W.; methodology, J.-H.Y and J.K.; software, W.-T.L. and S.-S.L.; validation, J.K., S.-S.L., and S.Y.; formal analysis, J.K.; writing-original draft preparation, W.-T.L; writing-review and editing, J.-H.Y. and J.-U.W.; visualization, J.-H.Y.; supervision, J.-U.W.; project administration, J.-U.W. All authors have read and agreed to the published version of the manuscript.

Funding: This research was funded by the Korean Society of Occupational and Environmental Medicine fund.

Acknowledgments: The authors would like to thank all the participants of the Korean Working Condition Survey.

Conflicts of Interest: The authors declare no conflict of interest.

\section{References}

1. Caruso, C.C. Negative impacts of shiftwork and long work hours. Rehabil. Nurs. 2014, 39, 16-25. [CrossRef] [PubMed]

2. Wong, I.S.; Smith, P.M.; Mustard, C.A.; Gignac, M.A. For better or worse? Changing shift schedules and the risk of work injury among men and women. Scand. J. Work Environ. Health 2014, 621-630. [CrossRef] [PubMed]

3. Virtanen, M.; Ferrie, J.E.; Singh-Manoux, A.; Shipley, M.J.; Stansfeld, S.A.; Marmot, M.G.; Ahola, K.; Vahtera, J.; Kivimaki, M. Long working hours and symptoms of anxiety and depression: A 5-year follow-up of the whitehall ii study. Psychol. Med. 2011, 41, 2485-2494. [CrossRef] [PubMed]

4. Ogawa, R.; Seo, E.; Maeno, T.; Ito, M.; Sanuki, M.; Maeno, T. The relationship between long working hours and depression among first-year residents in japan. BMC Med. Educ. 2018, 18, 50. [CrossRef] [PubMed]

5. Amagasa, T.; Nakayama, T. Relationship between long working hours and depression: A 3-year longitudinal study of clerical workers. J. Occup. Environ. Med. 2013, 55, 863-872. [CrossRef] [PubMed]

6. Kivimaki, M.; Jokela, M.; Nyberg, S.T.; Singh-Manoux, A.; Fransson, E.I.; Alfredsson, L.; Bjorner, J.B.; Borritz, M.; Burr, H.; Casini, A.; et al. Long working hours and risk of coronary heart disease and stroke: A systematic review and meta-analysis of published and unpublished data for 603,838 individuals. Lancet 2015, 386, 1739-1746. [CrossRef]

7. Vegso, S.; Cantley, L.; Slade, M.; Taiwo, O.; Sircar, K.; Rabinowitz, P.; Fiellin, M.; Russi, M.B.; Cullen, M.R. Extended work hours and risk of acute occupational injury: A case-crossover study of workers in manufacturing. Am. J. Ind. Med. 2007, 50, 597-603. [CrossRef]

8. Kecklund, G.; Axelsson, J. Health consequences of shift work and insufficient sleep. BMJ 2016, 355, i5210. [CrossRef]

9. Books, C.; Coody, L.C.; Kauffman, R.; Abraham, S. Night shift work and its health effects on nurses. Health Care Manag. 2017, 36, 347-353. [CrossRef]

10. McDowall, K.; Murphy, E.; Anderson, K. The impact of shift work on sleep quality among nurses. Occup. Med. 2017, 67, 621-625. [CrossRef]

11. Sleet, D.A.; Moffett, D.B. Framing the problem: Injuries and public health. Fam. Community Health 2009, 32, 88-97. [CrossRef] [PubMed]

12. Dembe, A.E. The social consequences of occupational injuries and illnesses. Am. J. Ind. Med. 2001, 40, 403-417. [CrossRef] [PubMed]

13. Farnacio, Y.; Pratt, M.E.; Marshall, E.G.; Graber, J.M. Are workplace psychosocial factors associated with work-related injury in the us workforce? National health interview survey, 2010. J. Occup. Environ. Med. 2017, 59, 164-171. [CrossRef] [PubMed] 
14. Ratzlaff, C.R.; Gillies, J.H.; Koehoorn, M.W. Work-related repetitive strain injury and leisure-time physical activity. Arthritis Rheum. 2007, 57, 495-500. [CrossRef]

15. Concha-Barrientos, M.; Nelson, D.I.; Fingerhut, M.; Driscoll, T.; Leigh, J. The global burden due to occupational injury. Am. J. Ind. Med. 2005, 48, 470-481. [CrossRef]

16. Arndt, V.; Rothenbacher, D.; Daniel, U.; Zschenderlein, B.; Schuberth, S.; Brenner, H. Construction work and risk of occupational disability: A ten year follow up of 14,474 male workers. Occup. Environ. Med. 2005, 62, 559-566. [CrossRef]

17. Murata, K.; Kawakami, N.; Amari, N. Does job stress affect injury due to labor accident in japanese male and female blue-collar workers? Ind. Health 2000, 38, 246-251. [CrossRef]

18. Holmes, N.; Triggs, T.J.; Gifford, S.M.; Dawkins, A. Occupational injury risk in a blue collar, small business industry: Implications for prevention. Saf. Sci. 1997, 25, 67-78. [CrossRef]

19. Kines, P. Occupational injury risk assessment using injury severity odds ratios: Male falls from heights in the danish construction industry, 1993-1999. Hum. Ecol. Risk Assess. 2001, 7, 1929-1943. [CrossRef]

20. Ministry of Employment and Labor (Ed.) The Status of Occupational Injury and Disease; Ministry of Employment and Labor: Sejong, Korea, 2019.

21. Paoli, P.; Merllié, D. Third European Survey on Working Conditions 2000; European Foundation for the Improvement of Living and Working Conditions: Dublin, UK, 2001.

22. Kim, Y.S.; Rhee, K.Y.; Oh, M.J.; Park, J. The validity and reliability of the second korean working conditions survey. Saf. Health Work 2013, 4, 111-116. [CrossRef]

23. Laflamme, L.; Eilert-Petersson, E. Injury risks and socioeconomic groups in different settings. Differences in morbidity between men and between women at working ages. Eur. J. Public Health 2001, 11, 309-313. [CrossRef] [PubMed]

24. Ministry of Employment and Labor (Ed.) Statistics of Industrial Accidents; Ministry of Employment and Labor: Sejong, Korea, 2018.

25. Spangenberg, S.; Baarts, C.; Dyreborg, J.; Jensen, L.; Kines, P.; Mikkelsen, K.L. Factors contributing to the differences in work related injury rates between danish and swedish construction workers. Saf. Sci. 2003, 41, 517-530. [CrossRef]

26. Dembe, A.E. The impact of overtime and long work hours on occupational injuries and illnesses: New evidence from the united states. Occup. Environ. Med. 2005, 62, 588-597. [CrossRef] [PubMed]

27. Dembe, A.E.; Delbos, R.; Erickson, J.B.; Banks, S.M. Associations between employees' work schedules and the vocational consequences of workplace injuries. J. Occup. Rehabil. 2007, 17, 641-651. [CrossRef]

28. Kang, S.-K.; Kwon, O.-J. Occupational injury statistics in korea. Saf. Health Work 2011, 2, 52-56. [CrossRef]

29. Dong, X. Long workhours, work scheduling and work-related injuries among construction workers in the united states. Scand. J. Work Environ. Health 2005, 31, 329-335. [CrossRef] [PubMed]

30. Yoon, J.-H.; Ahn, Y.-S. Cause-specific mortality due to malignant and non-malignant disease in Korean foundry workers. PLoS ONE 2014, 9, e88264. [CrossRef]

31. Breslin, F.C.; Dollack, J.; Mahood, Q.; Maas, E.T.; Laberge, M.; Smith, P.M. Are new workers at elevated risk for work injury? A systematic review. Occup. Environ. Med. 2019, 76, 694-701. [CrossRef]

32. Siu, O.-L.; Phillips, D.R.; Leung, T.-W. Age differences in safety attitudes and safety performance in hong kong construction workers. J. Saf. Res. 2003, 34, 199-205. [CrossRef]

33. Alcorso, C. Improving Occupational Health and Safety Information to Immigrant Workers in Nsw; Australian Centre for Industrial Relations Research and Training: Sydney, Australia, 2002.

34. Brogmus, G. Day of the week lost time occupational injury trends in the us by gender and industry and their implications for work scheduling. Ergonomics 2007, 50, 446-474. [CrossRef]

35. Nowrouzi-Kia, B.; Gohar, B.; Casole, J.; Chidu, C.; Dumond, J.; McDougall, A.; Nowrouzi-Kia, B. A systematic review of lost-time injuries in the global mining industry. Work 2018, 60, 49-61. [CrossRef]

36. Haines, P.S.; Hama, M.Y.; Guilkey, D.K.; Popkin, B.M. Weekend eating in the united states is linked with greater energy, fat, and alcohol intake. Obes. Res. 2003, 11, 945-949. [CrossRef]

37. Cantley, L.F.; Tessier-Sherman, B.; Slade, M.D.; Galusha, D.; Cullen, M.R. Expert ratings of job demand and job control as predictors of injury and musculoskeletal disorder risk in a manufacturing cohort. Occup. Environ. Med. 2016, 73, 229-236. [CrossRef] [PubMed] 
38. Lu, M.L.; Nakata, A.; Park, J.B.; Swanson, N.G. Workplace psychosocial factors associated with work-related injury absence: A study from a nationally representative sample of Korean workers. Int. J. Behav. Med. 2014, 21, 42-52. [CrossRef]

39. Ryu, J.; Jung-Choi, K.; Choi, K.-H.; Kwon, H.-J.; Kang, C.; Kim, H. Associations of shift work and its duration with work-related injury among electronics factory workers in south korea. Int. J. Environ. Res. Public Health 2017, 14, 1429. [CrossRef] [PubMed]

Publisher's Note: MDPI stays neutral with regard to jurisdictional claims in published maps and institutional affiliations.

(C) 2020 by the authors. Licensee MDPI, Basel, Switzerland. This article is an open access article distributed under the terms and conditions of the Creative Commons Attribution (CC BY) license (http://creativecommons.org/licenses/by/4.0/). 